\title{
A Review on the Adoption and Diffusion of Consumer Mobile Shopping in Mobile Networking Environment
}

\author{
Junhong HE Shangrong DU Zhixuan CHEN \\ School of Management \\ Guangdong University of Technology \\ Guangzhou, China \\ 2513474345@qq.com
}

\begin{abstract}
Mobile shopping means that consumers use mobile terminals such as mobile phone to do shopping through mobile network. As a new way of shopping, mobile shopping has advantages in portability, networking anytime and anywhere, mobile shopping provides personalized services and so on. Understanding consumers' shopping behaviors helps promote the development of mobile commerce. On the base of reviews on the mobile shopping, the paper focus on the review on the adoption and diffusion of consumer mobile shopping in mobile networking environment, and finally gives comments from research contents, research objects and research samples.
\end{abstract}

Key words—mobile shopping; user adoption; continuance intention

\section{INTRODUCTION}

As the current hot focus of technology, mobile commerce is beneficial to the business startups and innovation. However, in order to develop mobile commerce, promoting and popularizing mobile shopping is very important. At present, the number of mobile phone users is increasing all over the world. More and more people use mobile terminals instead of PC to get on the Internet. The statistics report from CNNIC shows that the proportion of using mobile phone to access to the Internet has increased 4.8\% by the end of December 2014, and this proportion keeps increasing. Also, 64.1\% new netizens used mobile phones to surf the Internet in $2014^{[1]}$. Because of this large amount of mobile Internet uses, many enterprises have paid more attention to business activities which can be conducted through mobile phones. More and more consumers begin to use mobile terminals to do shopping, which is defined as mobile shopping. The data from the China Electronic Commerce Research Center indicates that China's online retail size reached 1.0856 trillion yuan, and the transaction scale of mobile commerce in China reached 254.2 billion yuan, increasing to $378 \%$ by the end of June $2014^{[2]}$. Understanding consumers' mobile shopping behaviors helps promote the development of mobile commerce.

Supported by 2015 College Students Innovation and Entrepreneurship Training Program(Grant No.201511845145)

\section{ORIGIN AND DEVELOPMENT OF MOBILE SHOPPING}

In February 1999, Nokia has created the first Chinese dual-band mobile phone - the Nokia 7110 which supported WAP, marking the birth of mobile e-commerce terminal products. On February 23rd, 2000, Nokia and Amazon announced their global cooperation and provided WAP mobile phone users with mobile e-commerce services like finding and buying books from Amazon's huge online catalogs. Amazon officially opened mobile site in United Kingdom, which indicated that people could shopping online through WAP mobile phone ${ }^{[3]}$. From then on, mobile shopping era started.

Unfortunately, because the short-sighted mobile operators ignored the importance of developing users and made WAP service charge very high at first, the enthusiasm of Chinese WAP users was undermined, which caused the number of Chines users decreased gradually. What's more, Nokia 7110 failed to enter the potential consumer market due to its poor software stability even though it could support WAP. In subsequent years, the intelligent mobile terminals and mobile Internet encountered many obstacles. For example, it's very difficult for users to enter the long list of URL and search terms through mobile phones as the mobile phones' keyboard was too small. So the early development of mobile shopping was relatively slow.

However, mobile shopping met unprecedented opportunities because of the release of the original iPhone in 2007, the launch of 3G iPhone by Apple Corp on July 11, 2008, and the production of the first Android smart phone in October 2008.

In 2004, mobile shopping developed explosively. The data from CNNIC shows that mobile phone shopping market developed rapidly in 2014. The number of mobile shopping users was 236 million and its growth rate was 63.5\% which was 3.2 times as high as that in the whole online shopping market. Also, the proportion of mobile shopping usage increased from $13.5 \%$ to $42.4 \%$. Moreover, by the end of double-eleven shopping carnival in 2014, the turnover from Ali mobile terminal reached 24.3 billion yuan which was 3.54 times higher than that in last year and accounted for $42.6 \%$ of the total turnover of this year. In addition, the data from Jingdong showed that orders from mobile terminals accounted more than $40 \%$, which was 7 times higher than those in $2013^{[4]}$. All data mentioned above illustrates that mobile shopping era has arrived.

Facing this huge opportunity, various retailers begin to launch mobile network platform. For instance, Alibaba Group has launched a mobile platform called Taobao. Dangdang and Amazon have launched their own mobile shopping platforms too. What's more, more and more mobile applications have the function of shopping navigation, such as High Moral map, 
Meituan and so forth. However, mobile shopping is still a new way of shopping in China and Chinese mobile network has many drawbacks such as high cost and instability, so most of the potential Chinese consumers still in a wait-and-see state. Thus, in recent years, some scholars have done researches on how to enter the potential mobile shopping market, how to cause the potential consumers adopt this new shopping channel and how to stimulate the mobile shopping users to keep on using mobile shopping.

\section{ReseARCH OVERVIEW OF MOBILE SHOPPING}

Mobile shopping means that consumers use mobile terminals such as mobile phone to do shopping through mobile network $^{[5]}$. There are many concepts and interpretations of mobile shopping. Ozok \& Wei (2010) consider that mobile shopping, also known as mobile phone shopping, refers that consumers use mobile terminals such as mobile phone to do shopping through mobile network ${ }^{[6]}$. LW. Li(2014) believes that the mobile shopping service means that users trade products and serve through mobile devices ${ }^{[7]}$.To sum up, the mobile shopping is the extension of PC online shopping. Compared with the traditional online shopping, mobile shopping has difference in the terminal equipment, communication network, application environment and maturity of industry. We choose mobile shopping as search terms and use CSSCI Index in China as screening points to filtrate content from Baidu academic website. The result is shown in Table I.

Table I. Statistical table of mobile shopping literature

\begin{tabular}{|c|c|c|c|c|c|c|c|c|c|c|c|c|c|c|}
\hline & 2001 & 2002 & 2003 & 2004 & 2005 & 2006 & 2007 & 2008 & 2009 & 2010 & 2011 & 2012 & 2013 & \begin{tabular}{|l|l|}
2014 \\
\end{tabular} \\
\hline World Outlook & 1 & & & & & & & & & & & & & \\
\hline $\begin{array}{l}\text { Journal of Business } \\
\text { Economics }\end{array}$ & & & & 1 & & & & & & & & & & \\
\hline $\begin{array}{l}\text { New Technology of } \\
\text { Library and Information } \\
\text { Service }\end{array}$ & & & & & & & 1 & & & & & & & 1 \\
\hline Modern Information & & & & & & & & 1 & & & & & & 1 \\
\hline $\begin{array}{l}\text { Foreign Economics \& } \\
\text { Management }\end{array}$ & & & & & & & & & & 1 & & & & \\
\hline $\begin{array}{l}\text { Chinese Journal of } \\
\text { Management }\end{array}$ & & & & & & & & & & & & 1 & & \\
\hline Journal of Information & & & & & & & & & 1 & & & 2 & & \\
\hline Commercial Research & & & & & & & & & & & & & 1 & \\
\hline Media & & & & & & & & & & & & & 1 & 1 \\
\hline $\begin{array}{l}\text { Forum on Science and } \\
\text { Technology in China }\end{array}$ & & & & & & & & & & & & & 1 & \\
\hline Social Science F ront & & & & & & & & & & & & & & 1 \\
\hline Geographical Research & & & & & & & & & & & & & & 1 \\
\hline
\end{tabular}

In terms of research time, the research of online shopping began in United States in mid-1980s while the research of mobile shopping began in UK in 1999. At the beginning of the research, researchers focused on mobile applications and how mobile systems help consumers choose the goods. Chan (2000) presents a position-aware mobile shopping application called Deal Finder. Based on the consumers' position, this APP can filter any information for the consumers. Also, Deal Finder can show how collaboration among consumers help customers make more informed shopping decisions ${ }^{[8]}$. Kourouthanassis et al.(2002) proposes a mobile shopping system called My Grocer to solve the inefficiencies of retail grocery supply chain ${ }^{[9]}$.

In China, the earliest reference to mobile shopping appeared in 2001 while systematical research on mobile shopping began in 2003. In order to help operators of C2C websites conduct commodity auctions in WAP, Qing Q. Wu\& BS. Zhou(2003) illustrate a completed, advanced and safe mobile information service system ${ }^{[10]}$. From 2004 to 2008, most researchers still focused on mobile commerce, and mobile shopping was just simply introduced as a part of mobile commerce. For example, JZ. Yang (2004) writes an article to introduce e-commerce and suggest how to improve mobile marketing. And he simply mentions mobile sopping in the main business of mobile commerce ${ }^{[11]}$.
After 2008, some researchers began to pay attention to mobile shopping. Their research interests included mobile shopping system and technology, security issues of mobile shopping and consumer behavior in mobile shopping. From 2009 to 2014, among the academic journals which were affirmed by National Natural Science Foundation of China from CNKI, there were 7 articles about consumer behavior in mobile shopping, which means this field of research has become more and more popular.

However, there are just a few researches on mobile shopping in the world, not to mention the research about consumer behavior in mobile shopping. Therefore, it is necessary for us to review and discuss the new research interests of consumer behavior in mobile shopping.

\section{A ReView on the Adoption of Consumer Mobile SHOPPING}

The main theory of present study is the related theory of IT adoption and diffusion, such as Theory of Planned Behavior, Technology Adoption Model, Technology Adoption Model2, Innovation Diffusion Theory and so on. After we review the present study, we find that many factors can affect adoption of consumer mobile shopping. So, we classify these factors into two categories: personal factors and external factors. 


\section{A. Personal Factors}

Personal factors include consumers' self-efficacy, the nature of consumers, consumers' past experiences, demographic characters, consumers' habits and so on.

In terms of consumers' self-efficacy, CD. Zheng et al. (2012) finds that perceived usefulness, self-efficacy and perceived value affect intention to adopt mobile shopping, based on VAM and TAM ${ }^{[12]}$. Also, by combining TAM with TRI, Kumar (2013) argues that consumer's personality toward technology affects consumer perception toward mobile shopping. The result from Kumar's research shows that innovation, optimism, and insecurity influence perceptions directly while influence attitude and purchase intention indirectly ${ }^{[13]}$. Besides, relying on TPB which was put forward by Ajzen in 1999, Mishra(2014)illustrates that consumers' attitude and perceived behavioral control has positive and significant impacts on purchase intention, and subject norm has positive but insignificant impacts on purchase intention ${ }^{[14]}$.

In terms of consumers' past experiences and demographic characters, San-Martinn et al.(2015) find out that perceived entertainment has significant impact on young people who are under 25 years old and subjective norms have positive impact on adults who are over 25 years old ${ }^{[15]}$. What's more, Agrebia (2015) figures out that perceived enjoyment and consumer's satisfaction affect consumer's intention to use smart phone for mobile shopping positively ${ }^{[16]}$. In addition, Wanga et al. (2005) shows that after consumers adopt mobile shopping, their order rate would increase. Especially for low-spending consumers, once they are used to using mobile shopping, both their order rate and order size would increase ${ }^{[17]}$.

Also, some scholars choose consumers' trust as research interests and study how consumers' trust influence mobile shopping adoption. GM. Yang et al. (2009) assume that consumers' initial trust can influence their adoption towards mobile shopping. And perceived usefulness, tendencies in personal trust, structural security, business reputation and related groups have an effect on building consumers' initial trust towards mobile commerce ${ }^{[18]}$. Based on trust transfer theory, Yang et al.(2015)find that consumers' trust towards web shopping services and perceived integration between mobile shopping and web shopping positively influence consumers' trust towards mobile shopping services. This research also shows that trust transferring process has direct impact on behavior towards mobile shopping extension ${ }^{[19]}$.

\section{B. External Factors}

External factors include product and service, network platform, product promotion activities and so ${ }^{{ }^{[20]}}{ }^{[\mathrm{Wu}}$ (2006)determines 3 criteria of selecting mobile shopping site including assurance, merchandise and enabling function ${ }^{[21]}$. Compared consumer behavior traits, influences, decision-making process and behavioral patterns in traditional market environment with those in traditional networking environment, WH. Liao (2013) finds that consumer behavior is influenced by terminal capability, application environment traits, the cultural atmosphere of regional business in mobile networking environment, etc ${ }^{[22]}$.
In addition, some scholars consider that the influence of external factors can be represented by the perception of consumer. ML. Lu et al.(2012) demonstrates that perceived everywhere, perceived personality, perceived situation and perceived risk which are the main traits of mobile commerce can positively affect mobile shopping adoption ${ }^{[5]}$. Based on usage scenarios, SQ. Yang et al.(2012) builds a model of mobile internet adoption. He finds that usage scenarios have positively impact on perceived strength value, perceived hedonic value and mobile network adoption through this mode $^{[23]}$. Yang (2012) uses an extended TPB model, which includes level of experience of use, technology self-efficacy and technology innovation, to study mobile shopping behavior. The result shows that perceived enjoyment has significant impact on mobile shopping adoption. And consumers who are in different levels of technology traits have different attitudes towards mobile shopping adoption ${ }^{[24]}$. By building a SEM model of using intention towards wireless web shopping in mobile networking environment, WH. Liao\&XQ. Sun (2014) finds that perceived usefulness has a positive effect on shopping intention. Also, consumers' attitudes determine their shopping intentions ${ }^{[25]}$.

When scholars study the external factors which affect mobile shopping adoption, they follow the classical perspective of IT adoption theory. In other words, by analyzing and abstracting the inherent characteristics of a technology that are perceived by users, scholars can figure out users' attitude towards this technology and the reason why they adopt it.

To draw a conclusion, the theoretical basis for the study of mobile shopping adoption is relatively mature, so the researches of mobile shopping adoption which rely on TAM can come to a consistent result.

However, as researchers are accustomed to study mobile shopping adoption from the view of social psychology and technology, they seldom study or explore another new factor, such as marketing. Besides, marketing design is not only a new factor towards mobile shopping adoption but also a practical factor towards business operation. Also, there may be a positive correlation between marketing design and mobile shopping adoption.

\section{A ReVIEW ON THE Diffusion OF CONSUMER MOBILE SHOPPING}

This paper focuses on the researches on continuance intention to use mobile shopping and repurchase intention. However, after reviewing the domestic and foreign literature, we find that researches on continuance intention to use mobile shopping are still in the primary stage. And most researchers who study consumers' continuous usage towards a technology system usually rely on some models and theories, such as TAM, ECM-IT model, Requires Conformity Theory and so on. Nowadays, Expectation Confirmed Model (ECM) is the main model of continuous usage research. ECM thinks that before consumers use mobile shopping, they have psychological expectations. After consumers use mobile shopping, they have perceived performance. Comparing their psychological expectations with their perceived performance, consumers can feel the gap on their experience, called confirmation, which can affect consumers' perceived usefulness and satisfaction. And 
consumers' perceived usefulness and satisfaction have significant impact on repurchase intention. Following this model, researchers have done some research on continuance intention to use mobile shopping during these years. For instance, HM. Lee(2014)adds two new variables (perceived quality, perceived usefulness) into ECM. With this extended ECM, HM. Lee finds that perceived quality of information, perceived quality of system and perceived quality of service have significant impact on confirmation. And confirmation and perceived usefulness positively affect satisfaction which affect continuance intention ${ }^{[26]}$. What's more, based on ECM, Q. Zhao (2013) illustrates that perceived costs, trust, privacy concerns and satisfaction are driving factors which influence continuous usage of mobile commerce ${ }^{[27]}$. In addition, by using Technology Adoption Model and extended ECM which includes extra factors such as perceived costs, perceived usefulness, perceived enjoyment and trust, Chong(2013) proves that perceived costs, perceived usefulness, perceived enjoyment, consumers' trust and satisfaction have an effect on continuous usage of mobile commerce ${ }^{[28]}$. In the perspective of self - help travelers, JL. Lu et al. (2013) uses ECM-IT to study continuance intention towards mobile network. The result shows that requires conformity positively influences perceived costs, perceived usefulness, perceived enjoyment and perceived ease of use. And expectation conformity positively influences perceived costs and perceived usefulness. In addition, perceived costs, perceived usefulness, perceived enjoyment, perceived ease of use and satisfaction have significant impact on continuance intention ${ }^{[29]}$. Based on ECM, Xuan Zhang\&Qinglie Wu (2010) put forward another three scaling factors (perceived enjoyment, perceived costs, switching costs) and makes ECM become an extended ECM. By analyzing this extended ECM, X. Zhang\&QL. Wu find that confirmation, perceived enjoyment, perceived costs, switching costs, perceived usefulness and satisfaction determine whether consumers continue to use mobile commerce. And satisfaction which is influenced by confirmation, perceived enjoyment, perceived costs and perceived usefulness is a driving factor towards continuance intention ${ }^{[30]}$.

\section{COMMENTARY}

Above all, even though many scholars have done many researches on consumer mobile shopping behavior, weak links still exist.

Firstly, the researches on mobile shopping initial adoption are still not perfect. A lot of researchers have done many related research on mobile shopping initial adoption, but most of them only study the classic variables such as perceived costs, perceived usefulness, perceived enjoyment and a few of them study new variables. Also, the researchers are used to using classic theories and models such as TPB, TAM, TAM2, UTAUT, IDT, TTF and so on but few of them have come up with new theories and models to study mobile shopping initial adoption. In fact, compared with traditional online shopping, mobile shopping has advantages in portability, networking anytime and anywhere, providing personalized services, which can be explored. Therefore, we can do some researches on some moderating variables. For example, in the perspective of product segmentation, we can study how categories of products affect mobile shopping initial adoption. As we know, consumers have different requirements towards different products. So once they adopt mobile shopping as a shopping channel, different categories of products would give consumers different mobile shopping experience, which in return affect mobile shopping adoption. Higgins et al.(2014)studies the effect of QR codes and mobile application in the wine buying decision. The result shows that wine buyers who consider themselves as wine experts are more likely to use mobile application, QP codes or other technology when they are making decision about buying locally produced and organic wine $^{[31]}$. Khajehzadeh et al.(2014) also illustrates that when consumers have mobile coupons, utilitarian shoppers and hedonic shoppers have different shopping motivation ${ }^{[32]}$.In conclusion, we should study some new moderating variables in the future researches.

Secondly, the researches on the continuous diffusion behavior of mobile shopping are very vacant, even though many researchers have done researches on this topic during these years. The main reason is that most researchers adopt ECM to study continuous diffusion behavior of mobile shopping. Expectation Confirmed Model (ECM), which was put forward by Olive in 1980, focuses on the gap between consumers' psychological expectations and consumer's perceived performance. That is, if researchers adopt this model to start their researches, they should repeatedly measure the same sample which is very hard. And that is the reason why the researches on the continuous diffusion behavior of mobile shopping are very vacant.

Thirdly, the researches on the adoption and diffusion of consumer mobile shopping are very rare. Nowadays, most researchers only focus on mobile shopping adoption, but few of them would combine mobile shopping diffusion with mobile shopping adoption so that they can study consumer behavior completely. Also, when scholars study consumer behavior, they prefer to use Theory of Reasoned Action. Unfortunately, the Theory of Reasoned Action can be only used to study stage of adoption, and it fails to explain and predict consumer continuance intention. Therefore, the present studies, which rely on TAM or TRA, can't tell difference between stage of adoption and stage or stage of diffusion, let alone combine two stages together. However, Wanga et al.(2005) finds that after consumers adopt mobile shopping, their order rate would increase. Especially for low-spending consumers, once they are used to using mobile shopping, both their order rate and order size would increase ${ }^{[17]}$. Agrebia et al.(2015) also illustrate that purchasers'(who have the experience of mobile shipping) intentions to use smart phone for buying are different from non-purchasers'(who don't have the experience of mobile shipping $)^{[16]}$. So, it is very necessary for us to study he adoption and diffusion of consumer mobile shopping.

Fourthly, the choice of the sample has deficiencies. The recent samples of the researches on the adoption and diffusion of consumer mobile shopping are just normal people, which never be segmented and compared. However, as mobile shopping is a new shopping channel, different people (e.g. students and middle-aged people) would hold different attitude towards it. Besides, according to Diffusion of Innovation Theory, the individual in the same group can be divided into an innovator, early adopter, early follow-up, late follow-up and 
laggard in accordance with their acceptance and usage of innovation. Obviously, people in different stages have different traits. In terms of demographics, people with different gender, age and job have different adoption intention and continuance intention. For instance, when San-Martinn et al. study consumers who have the experience of mobile shopping, he finds that people under 25 years old are affected by perceived enjoyment, while people over 25 years old are affected by subjective norm. Therefore, in the future study, we should segment the samples. By comparing and analyzing these samples, we can know the result of adoption and diffusion of consumer mobile shopping better ${ }^{[15]}$.

Fifthly, most researches adopt the same classic research methods such as questionnaire survey, structural equation model, multiple regression analysis and factorial analysis. And this is the reason why our researches stop in the stage of adoption and can move into next stage (stage of diffusion). Besides, this phenomenon would block the new development of research methods. As more and more researchers study consumer behavior in mobile shopping, new research methods such as experimental research and case study should be tried and paid more attention to.

\section{ACKNOWLEDGMENT}

The authors acknowledge the financial support by 2015 College Students Innovation and Entrepreneurship Training Program-A Review on the Adoption and Diffusion of Consumer Mobile Shopping in Mobile Networking Environment(201511845145). The authors are grateful to the anonymous referee for a careful checking of the details and for helpful comments that improved this paper.

\section{REFERENCES}

[1] The thirty-fifth China internet network development statistics report released by CNNIC [J]. The website of China Distance Education, 2015.

[2] The monitoring report of China online retail market data 2014 from China E-business Research Center , 2014, www.100ec.cn.

[3] The choice of the new century-mobile e-commerce [J]. Journal of Chinese conversion, 2000.

[4] R. Rong. Double-eleven shopping carnival- mobile commerce carnival era is coming, China Business Journal,2014.11.17, Page 8.

[5] ML. Lu, YZ. Cao, YB. Lu.A study on consumers' adoption of mobile shopping services from a perspective of features in the mobile environment [J]. Journal of intelligence, 2012, pp.202-206.

[6] AA. Ozok, J. Wei. An empirical comparison of consumer usability preferences in online shopping using stationary and mobile devices: results from a college student population [J]. Electronic Commerce Research, 2010, vol.10(2), pp.111-137.

[7] LW. Li. A literature review on mobile commerce services and user adoption behavior [J]. Journal d Modem Information, 2014, vol.34, pp.171-176.

[8] W. Chan. DealFinder: A Collaborative, Location-Aware Mobile Shopping Application [J]. 2001,

[9] P. Kourouthanassis, D. Spinellis, G. Roussos, et al. Intelligent Cokes and Diapers: MyGROCER Ubiquitous Computing Environment [J]. In: Proceedings of The First International Conference on Mobile Business M-business '02, 2002.
[10] Q. Wu\& BS. Zhou. The design of mobile shopping system based on WAP [J]. Computer Era, 2003, pp.12-13.

[11] JZ. Yang. Mobile e-commerce marketing strategy [J]. Business Economics and Administration, 2004, pp.4-7.

[12] CD. Zhen, X. Liu, X. Yang. Impact of perceived value and individual cognition on consumers' adoption intention of mobile shopping [J]. Chinese Journal of Management, 2012, vol.09, pp.1524-1530.

[13] A. Kumar \& A. Mukherjee. Shop while you talk: Determinants of purchase intentions through a mobile device [J]. International Journal of Mobile Marketing, 2013, vol.8(1) , pp. 23-37.

[14] S. MISHRA. Adoption of m-commerce in India: applying theory of planned behaviour model [J]. Journal of Internet Banking and Commerce, 2014, 19(1):

[15] S. San-Martín , J. Prodanova, N. Jiménez. The impact of age in the generation of satisfaction and WOM in mobile shopping [J]. Journal of Retailing and Consumer Services, 2015, pp.1-8.

[16] S. Agrebi, J. Jallais, S. Agrebi, et al. Explain the intention to use smart phones for mobile shopping [J]. Journal of Retailing and Consumer Services, 2014.

[17] RJ-H. Wang , EC. Malthouse, L. Krishnamurthi. On the go: how mobile shopping affects customer purchase behavior [J]. Journal of Retailing, 2015.

[18] GM. Yang,YB. Lu,W. Liu. An empirical research on factors influencing consumers' in initial trust in mobile commerce [J]. Journal of intelligence, 2009, vol.28, pp.175-179.

[19] S. Yang, Y. Chen, J. Wei Understanding consumers' web-mobile shopping extension behavior :a trust transfer perspective [J]. Journal of Computer Information Systems, 2015.

[20] QB. Xie. Research on mobile buyers behavior and marketing strategy [J]. Journal of Yangtze University(Social Sciences), 2009, vol. 32 No. 4.

[21] JH. Wu, YM. Wang. Development of a tool for selecting mobile shopping site: A customer perspective [J]. Electronic Commerce Research and Applications, 2006, vol.5(3), pp.192-200.

[22] WH. Liao. Research on consumer behavior in mobile internet [J]. Science and Technology Management Research, 2013, vol.33,pp.179-83.

[23] SQ. Yang,YB. Lu,YZ. Cao. The effects of use context on consumer's intention to adopt mobile internet service [J]. Journal of intelligence, 2012, pp.182-188.

[24] K. Yang. Consumer technology traits in determining mobile shopping adoption: An application of the extended theory of planned behavior [J]. Journal of Retailing and Consumer Services, 2012, vol.19(5), pp. 484-491.

[25] WH. Liao\&XQ. Sun.SEM model of mobile Internet consumers' shopping intention [J]. Modern Business Trade Industry, 2012, vol.24, pp.271-273.

[26] HM. Lee.Perceived quality as a key antecedent in continuance intention on mobile commerce[J]. International Journal of Electronic Commerce Studies, 2014, vol.5(2), pp.123-142.

[27] Q. Zhao,GQ. Liang,Q. Wang. Study on continuance usage model of mobile commerce [J]. Science and Technology Management Research, 2013, vol.33, pp.249-253.

[28] LY-L. Chong.Understanding mobile commerce continuance intentions:an empirical analysis of Chinese consumers[J]. Journal of Computer Information Systems Summer, 2013, pp.22-30.

[29] JL. Lu,Y. Sun,XL. Wang.Research on mobile internet uses' continuance intentions:In the perspective of self-help travelers [D].Journal of Zhejiang University, 2010.

[30] X. Zhang\&QL. Wu. Research on the Continued Usage Intention of mobile commerce based on expanded ECM [J]. Journal of Taiyuan University of Technology, 2010, vol.41, pp.28-32.

[31] LM. Higgins, MM. Wolf, MJ. Wolf. Technological change in the wine market? The role of QR codes and wine apps in consumer wine purchases [J]. Wine Economics and Policy, 2014, vol.3, pp.19-27.

[32] S. Khajehzadeh, H. Oppewal, D. Tojib. Consumer responses to mobile coupons: The roles of shopping motivation and regulatory fit [J]. General information, 2014, vol.67(11), pp.2447-2455. 